\title{
Asymmetric Total Synthesis of (+)-Merobatzelladine B
}

\author{
Nicholas R. Babij and \\ Department of Chemistry, University of Michigan, 930 N. University Ave, Ann Arbor, MI \\ 48109-1055, USA \\ John P. Wolfe [Professor] \\ Department of Chemistry, University of Michigan, 930 N. University Ave, Ann Arbor, MI \\ 48109-1055, USA \\ John P. Wolfe: jpwolfe@umich.edu
}

\begin{abstract}
The first total synthesis of (+)-merobatzelladine B was accomplished using an iterative sequence of stereoselective Pd-catalyzed alkene carboamination reactions for formation of two of the three rings. This represents a new strategy for the generation of polycyclic guanidine natural products, and provides access to compounds with a syn-relationship between the $\mathrm{C} 6 \mathrm{H}$-atom and the $\mathrm{C} 8$ alkyl group.
\end{abstract}

\section{Keywords}

Alkaloids; Natural Products; Asymmetric Synthesis; Palladium; Stereoselective

Polycyclic guanidine natural products, such as batzelladines A, E, and F, exhibit a rich and diverse array of interesting biological activities (Figure 1). ${ }^{[1,2]}$ Some polycyclic guanidine alkaloids have been shown to inhibit protein-protein interactions, including binding of HIV gp120 to CD4 on human T-cells. In addition, many polycyclic guanidines display potent antiviral, antimalarial, and immunosuppressive properties.

In 2009 Matsunaga et.al. reported the isolation of merobatzelladines A and B (4 and 5) from the marine sponge Monanchora sp. (Figure 2). ${ }^{[3]}$ These compounds are members of a new sub-class of the batzelladine alkaloids that possess the signature tricyclic guanidine core common to all batzelladines, but display a unique stereochemical feature that differs from other members in this family. The $\mathrm{C} 8$ alkyl substituents in merobatzelladines $\mathrm{A}$ and B are positioned in a syn-relationship with the C6 hydrogen atoms, whereas other related natural products, such as batzelladines A, E, or F (1-3), contain an anti-relationship between these groups. Merobatzelladines A and B exhibit moderate antimicrobial activity against Vibrio anguillarum, and also show inhibitory activity against the K1 strain of Plasmodium falciparum $\left(\mathrm{IC}_{50}=0.48 \mu \mathrm{g} / \mathrm{mL}\right.$ and $0.97 \mu \mathrm{g} / \mathrm{mL}$, respectively). Given the rich biological activity of the related batzelladine alkaloids, it is possible that merobatzelladines A and B may exhibit additional useful properties that have yet to be reported.

Given the importance of polycyclic guanidine alkaloids, several different approaches have been employed for the synthesis of these compounds. The most widely utilized routes typically generate the fused ring system through condensation reactions, ${ }^{[4]}$ cycloaddition

Correspondence to: John P. Wolfe, jpwolfe@umich.edu.

Supporting information for this article is available on the WWW under http://www.angewandte.org or from the author. 
reactions, ${ }^{[5]}$ radical cyclizations, ${ }^{[6]}$ and substitution reactions. ${ }^{[7]}$ Although these routes have proven highly useful, none provide a means for generation of a $\mathrm{C}-\mathrm{C}$ bond adjacent to the ring (such as the $\mathrm{C}^{\prime}-\mathrm{C}_{4} \mathrm{H}_{9}$ bond in $\mathbf{5}$ ) during the ring-closing event. In addition, none of these routes have been employed for the generation of molecules with the syn-relationship between the $\mathrm{C} 8$ alkyl group and the $\mathrm{C} 6 \mathrm{H}$-atom such as that displayed in merobatzelladines $\mathrm{A}$ and $\mathrm{B}$. In this communication we describe the first total synthesis of merobatzelladine B (5), which provides the natural product as a single stereoisomer in high optical purity, and represents a new strategy for the construction of polycyclic guanidine alkaloids.

Our approach to the synthesis of merobatzelladine B was centered around the use of Pdcatalyzed alkene carboamination reactions for the formation of two of the three rings in the natural product. ${ }^{8}$ As shown in Scheme 1, we envisioned that a Pd-catalyzed carboamination between vinyl bromide and an appropriately functionalized $\gamma$-aminoalkene derivative $\mathbf{6}$ would generate cis-disubstituted pyrrolidine 7 with high stereocontrol. A second carboamination reaction between allylpyrrolidine derivative $\mathbf{8}$ and 1-bromo-1-butene would afford bicyclic product 9 , which could then be transformed to the polycyclic guanidine natural product 5 through functional group interconversion and ring-closure via an intramolecular $\mathrm{S}_{\mathrm{N}} 2$ reaction.

Our prior studies on Pd-catalyzed alkene carboamination reactions have illustrated that the conversion of $\mathrm{N}$-boc- $\gamma$-aminoalkenes to 2,5 -disubstituted pyrrolidines typically proceeds in good yield with $>20: 1$ diastereoselectivity favoring the cis-isomer. ${ }^{[8,9]}$ As such, the transformation of $\mathbf{6}$ to $\mathbf{7}$ appeared quite feasible; however, the likelihood of success in the planned Pd-catalyzed carboamination between $\mathbf{8}$ and an alkenyl halide was less clear. The generation of six-membered rings via Pd-catalyzed carboamination is considerably more difficult than formation of five-membered rings, ${ }^{[10]}$ and this has not previously been accomplished with an unsaturated urea substrate. ${ }^{[11]}$ To test the feasibility of this key transformation, we examined the Pd-catalyzed carboamination of 2-allyl-pyrrolidine-derived urea 11 with simple aryl and alkenyl halides. After optimization of conditions, we found that a catalyst composed of $\mathrm{Pd}_{2}(\mathrm{dba})_{3} / \mathrm{PCy}_{3}$ provided satisfactory results in these reactions (Scheme 2). The bicyclic urea products 12a-b were obtained in good yield and high diastereoselectivity, which may arise via cyclization through boat-like transition state 13. ${ }^{[10 b, c, 12]}$ The alternative boat-like transition state $\mathbf{1 4}$, which leads to the minor diastereomer, appears to suffer from significant steric interactions between the alkene and the pyrrolidinyl ring. Moreover, cyclization through a chair-like transition state appears to be less accessible due to poor overlap between the alkene pi-system and the $\mathrm{Pd}-\mathrm{N}$ bond. ${ }^{[10 b, c]}$

Having illustrated the feasibility of our approach to the generation of fused bicyclic ureas, we undertook the synthesis of merobatzelladine B by constructing an appropriately functionalized $\gamma$-aminoalkene derivative for the pyrrolidine-forming carboamination. As shown in Scheme 3, the amine-bearing stereocenter was generated via a highly efficient asymmetric Mannich reaction of sulfinyl imine 16. ${ }^{[13]}$ The stereocontrolled reduction of ketone 17 proved quite challenging, ${ }^{[14]}$ and after examining many different reducing agents we found that the combination of $\mathrm{NaBH}_{4}$ and $\mathrm{CeCl}_{3}$ led to formation of 18 with 3:1 diastereoselectivity. However, the two diastereomers were separable by column chromatography, and $\mathbf{1 8}$ was isolated as a single stereoisomer in 63\% yield. Protection of the alcohol as a benzyl ether followed by exchange of the sulfinyl group for a boc-group provided 19 in $91 \%$ yield over three steps and $99 \%$ ee.

With intermediate 19 in hand, the key sequence of carboamination reactions was undertaken (Scheme 4). The Pd/P(2-furyl) 3 -catalyzed carboamination of 19 with $E$-2bromovinyltrimethylsilane provided pyrrolidine $\mathbf{2 0}$ in $68 \%$ yield and with excellent 
stereocontrol (>20:1 dr). ${ }^{[15]}$ Treatment of $\mathbf{2 0}$ with TFA led to cleavage of the boc group and protodesilylation of the alkene. The resulting pyrrolidine was coupled with $p$ methoxybenzylisocyanate to generate pyrrolidinyl urea $\mathbf{2 1}$ in $\mathbf{7 2 \%}$ yield over the two-step sequence. ${ }^{[16]} \mathrm{The} \mathrm{Pd} / \mathrm{PCy}_{3}$-catalyzed carboamination of $\mathbf{2 1}$ with $Z$-1-bromo-1-butene proceeded smoothly to yield bicyclic urea $\mathbf{2 2}$ in $91 \%$ yield and $>20: 1 \mathrm{dr}$.

Bicyclic urea $\mathbf{2 2}$ was converted to guanidinium salt $\mathbf{2 3}$ in $89 \%$ yield by treatment with $\mathrm{POCl}_{3}$ followed by addition of ammonia (Scheme 5). ${ }^{[17]}$ The tetrafluoroborate counterion was introduced during the workup procedure by washing a dichloromethane solution of the crude guanidine product with aqueous $\mathrm{NaBF}_{4}$. This anion exchange was essential to avoid complications during the subsequent ring-closing step. ${ }^{[18]}$ Guanidinium salt $\mathbf{2 3}$ was then transformed to the natural product $\mathbf{5}$ in a three-step sequence involving initial hydrogenation with $\mathrm{Pd} / \mathrm{C}$ to effect reduction of the alkene and cleavage of the benzyl ether protecting group. Ring-closure was achieved via an intramolecular Mitsunobu reaction, ${ }^{[7 \mathrm{a}]}$ and deprotection of the $N$-PMB group provided merobatzelladine B (5) in $41 \%$ yield over the three step sequence from 23. The synthetic alkaloid was obtained in enantiopure form $\left\{[a]^{23} \mathrm{D}+40.1(c 0.7, \mathrm{MeOH})\left[\mathrm{lit}^{[3]}[\mathrm{a}]^{23} \mathrm{D}+27(c 0.15 \mathrm{MeOH})\right]\right\}$, and NMR spectra were identical to the data previously reported for the natural product. ${ }^{[3]}$

In summary, we have developed the first asymmetric total synthesis of (+)-merobatzelladine B (5), which confirms the structural and stereochemical assignments of the natural product. Our route afforded the desired alkaloid in 15 steps and 6.7\% overall yield from commercially available pent-4-enal (15). The results described above represent a fundamentally new strategy for the stereocontrolled synthesis of polycyclic guanidine natural products. This new approach allows for formation of a carbon-carbon bond during the ring-closing event, and is the first route shown to provide access to alkaloids with a synrelationship between the C6 hydrogen atom and the C8 alkyl group. This strategy could potentially be employed to access other guanidine alkaloids that contain this stereochemical feature, and could also be used for the generation of novel analogs of the batzelladine alkaloids. In addition, this work also illustrates the feasibility of forming 5,6-fused bicyclic urea ring systems via Pd-catalyzed carboamination, which could be of value for preparation of other interesting biologically active heterocycles.

\section{Supplementary Material}

Refer to Web version on PubMed Central for supplementary material.

\section{Acknowledgments}

The authors acknowledge the NIH-NIGMS (GM 098314) and the University of Michigan Associate Professor Support Fund for financial support of this work. Additional funding was provided by GlaxoSmithKline and Amgen.

\section{References}

1. a) Berlinck RGS, Burtoloso ACB, Trindade-Silva AE, Romminger S, Morais RP, Bandeira K, Mizuno CM. Nat Prod Rep. 2010; 27:1871-1907. [PubMed: 20957265] b) Berlinck RGS, Burtoloso ACB, Kossuga MH. Nat Prod Rep. 2008; 25:919-954. [PubMed: 18820759] c) Berlinck RGS, Kossuga MH. Nat Prod Rep. 2005; 22:516-550. [PubMed: 16047049] d) Bewley CA, Ray S, Cohen F, Collins SK, Overman LE. J Nat Prod. 2004; 67:1319-1324. [PubMed: 15332849]

2. a) Patil AD, Kumar NV, Kokke WC, Bean MF, Freyer AJ, De Brosse C, Mai S, Truneh A, Faulkner DJ, Carte B, Breen AL, Hertzberg RP, Johnson RK, Westley JW, Potts BCM. J Org Chem. 1995; 60:1182-1188.b) Snider BB, Chen J. Tetrahedron Lett. 1998; 39:5697-5700.

3. a) Takishima S, Ishiyama A, Iwatsuki M, Otoguro K, Yamada H, Omura S, Kobayashi H, van Soest RWM, Matsunaga S. Org Lett. 2009; 11:2655-2658. [PubMed: 19469518] b) Takishima S, 
Ishiyama A, Iwatsuki M, Otoguro K, Yamada H, Omura S, Kobayashi H, van Soest RWM, Matsunaga S. Org Lett. 2010; 12:896.

4. a) Murphy PJ, Williams HL, Hursthouse MB, Abdul Malik KM. J Chem Soc, Chem Commun. 1994:119-120.b) Snider BB, Chen J, Patil AD, Freyer AJ. Tetrahedron Lett. 1996; 37:6977-6980.c) Cohen F, Overman LE. J Am Chem Soc. 2001; 123:10782-10783. [PubMed: 11674029] d) Overman LE, Wolfe JP. J Org Chem. 2001; 66:3167-3175. [PubMed: 11325284] e) Aron ZD, Overman LE. Chem Comm. 2004:253-265. [PubMed: 14740029]

5. a) Arnold MA, Day KA, Duron SG, Gin DY. J Am Chem Soc. 2006; 128:13255-13260. [PubMed: 17017806] b) Butters M, Davies CD, Elliott MC, Hill-Cousins J, Kariuki BM, Ooi L-L, Wood JL, Wordingham SV. Org Biomol Chem. 2009; 7:5001-5009. [PubMed: 19907792]

6. Evans PA, Qin J, Robinson JE, Bazin B. Angew Chem. 2007; 119:7561-7563.Angew Chem Int Ed. 2007; 46:7417-7419.

7. Ishiwata T, Hino T, Koshino H, Hashimoto Y, Nakata T, Nagasawa K. Org Lett. 2002; 4:29212924. [PubMed: 12182589]

8. For reviews on Pd-catalyzed alkene carboamination reactions, see: Wolfe JP. Synlett. 2008:29132937.Schultz DM, Wolfe JP. Synthesis. 2012; 44:351-361.

9. a) Bertrand MB, Neukom JD, Wolfe JP. J Org Chem. 2008; 73:8851-8860. [PubMed: 18942792] b) Bertrand MB, Wolfe JP. Tetrahedron. 2005; 61:6447-6459.

10. a) Nakhla JS, Wolfe JP. Org Lett. 2007; 9:3279-3282. [PubMed: 17650007] b) Nakhla JS, Schultz DM, Wolfe JP. Tetrahedron. 2009; 65:6549-6570. [PubMed: 20640043] c) Leathen ML, Rosen BR, Wolfe JP. J Org Chem. 2009; 74:5107-5110. [PubMed: 19480462]

11. a) Fritz JA, Nakhla JS, Wolfe JP. Org Lett. 2006; 8:2531-2534. [PubMed: 16737306] b) Fritz JA, Wolfe JP. Tetrahedron. 2008; 64:6838-6852. [PubMed: 19122758]

12. For further details on the mechanism of Pd-catalyzed alkene carboamination, see: Neukom JD, Perch NS, Wolfe JP. Organometallics. 2011; 30:1269-1277.Neukom JD, Perch NS, Wolfe JP. J Am Chem Soc. 2010; 132:6276-6277. [PubMed: 20397666]

13. a) Davis FA, Yang B. Org Lett. 2003; 5:5011-5014. [PubMed: 14682752] b) Tang TP, Ellman JA. J Org Chem. 2002; 67:7819-7832. [PubMed: 12398509]

14. Davis FA, Gaspari PM, Nolt BM, Xu P. J Org Chem. 2008; 73:9619-9626. [PubMed: 18986203]

15. 2-Bromovinyltrimethylsilane was used in place of vinyl bromide due to the volatility of the latter compound.

16. The PMB protecting group was employed due to the relative ease of deprotection as compared to the PMP group used in the model study.

17. This transformation must be conducted under rigorously anhydrous conditions to avoid $\mathrm{HCl}-$ mediated side reactions.

18. Use of the analogous guanidinium chloride salt in the ring-closing Mitsunobu reaction led to the formation of a chlorinated side product resulting from chloride for hydroxyl group substitution. In addition, a diastereomeric side product resulting from double inversion at $\mathrm{C} 1$ was also formed. Use of the $\mathrm{BF}_{4}$ salt prevented formation of these side products. 


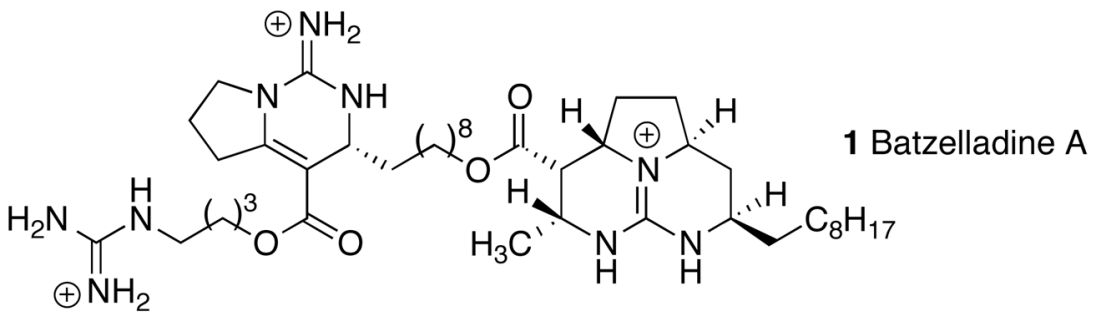

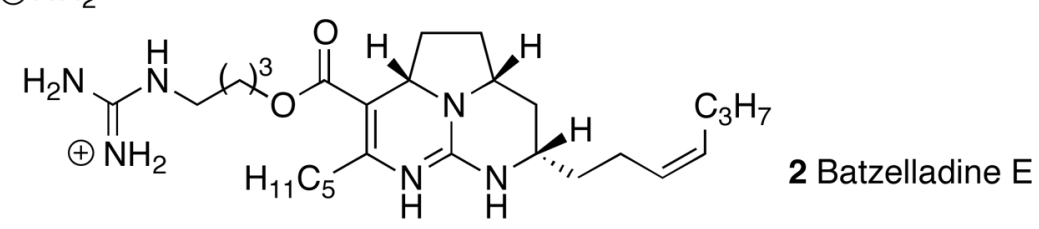

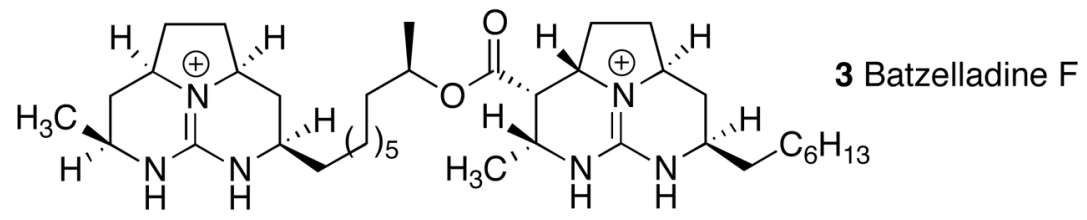

Figure 1.

Polycyclic guanidine natural products 


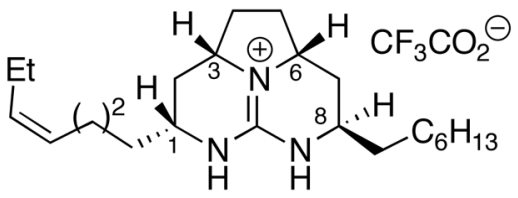

4 Merobatzelladine A

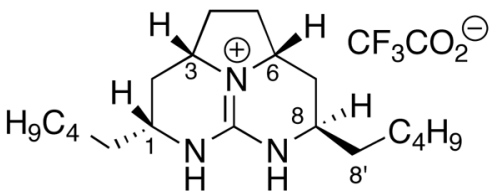

5 Merobatzelladine B

Figure 2.

Merobatzelladine alkaloids 
<smiles>C=CCCC(CC(C)CC)NC(=O)OCCC</smiles>

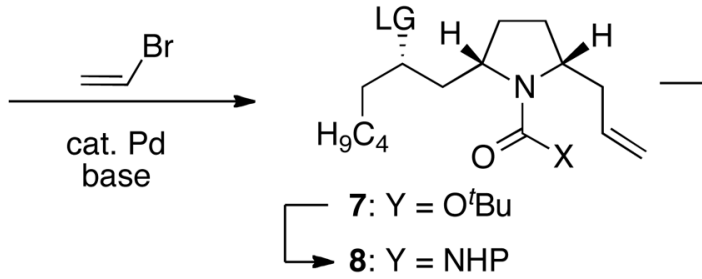<smiles></smiles>

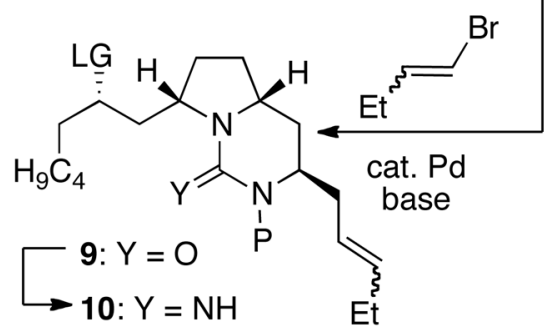

Scheme 1.

Iterative carboamination strategy for polycyclic guanidine synthesis. 


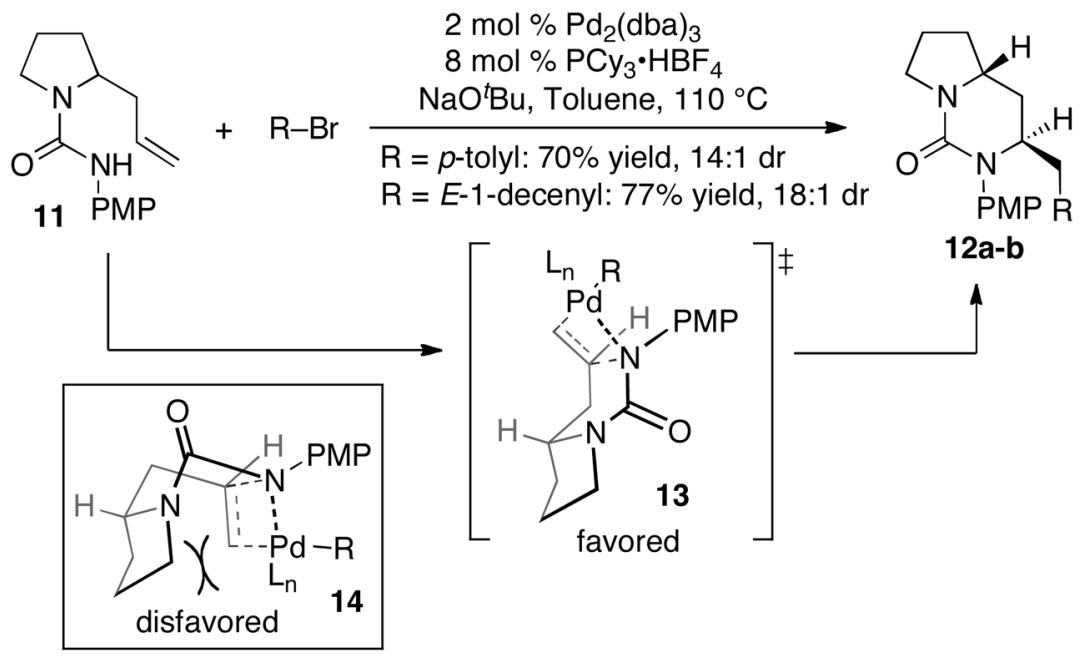

Scheme 2.

Synthesis of bicyclic ureas via Pd-catalyzed carboamination. 


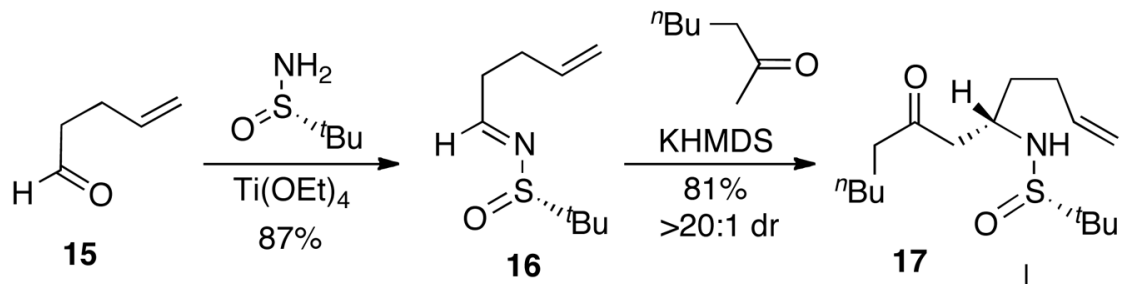

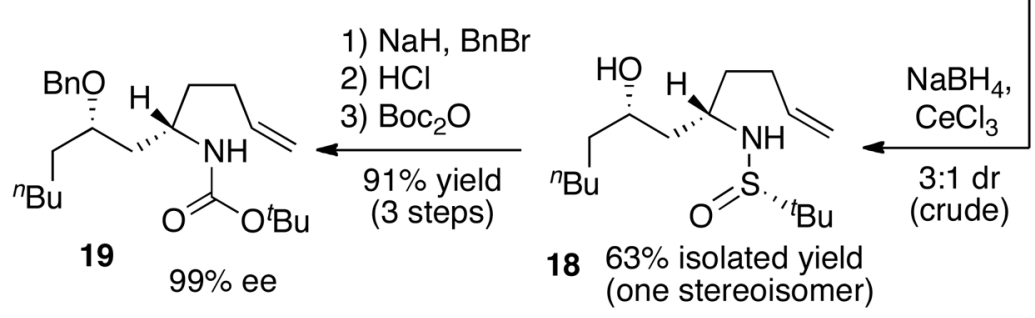

Scheme 3.

Synthesis of $\gamma$-aminoalkene 19. 


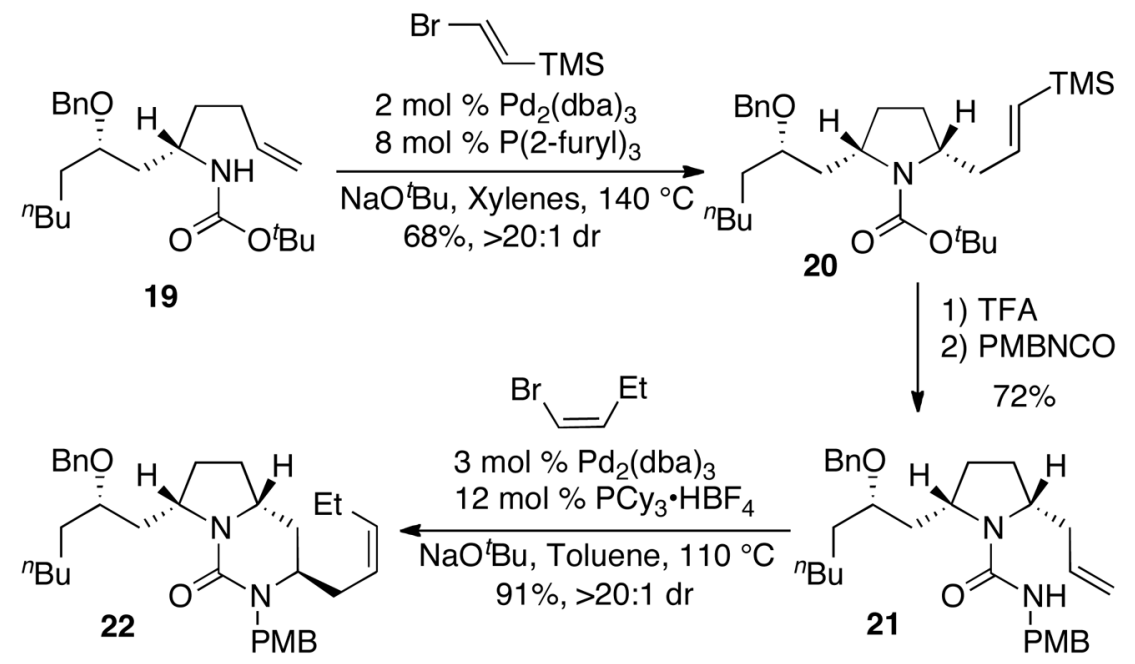

Scheme 4.

Carboamination reaction sequence for bicyclic urea construction. 


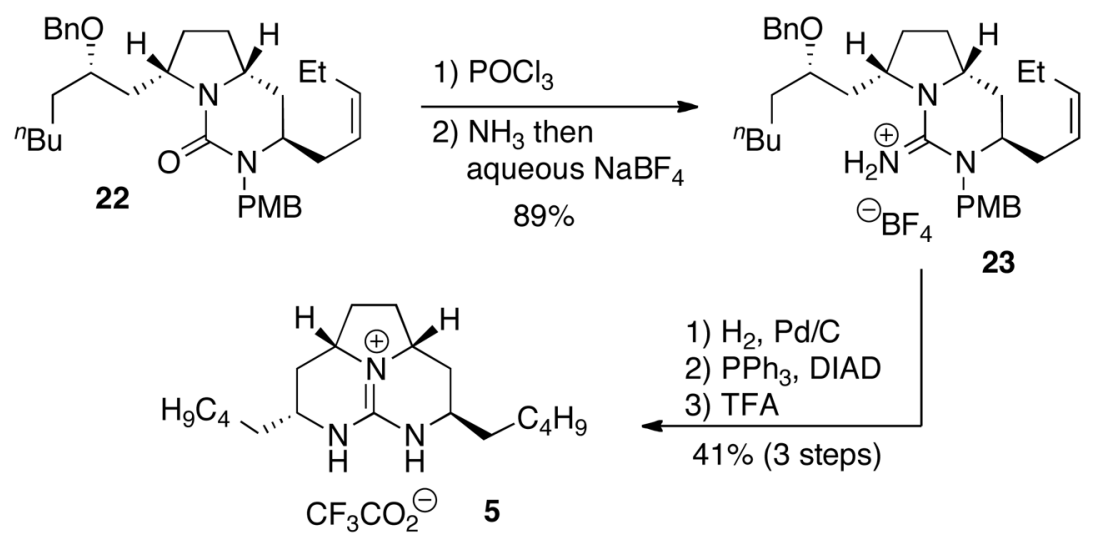

Scheme 5.

Completion of the synthesis. 